\title{
The effects of increasing doses of 2 preparations of long-acting insulin on short-term plasma profiles of glucose and insulin in lactating dairy cows
}

\author{
L. A. Winkelman ${ }^{1}$ and T. R. Overton ${ }^{2}$ \\ Department of Animal Science, Cornell University, Ithaca, NY 14853
}

\begin{abstract}
Two experiments were conducted to investigate effects of administering increasing doses of 2 different preparations of long-acting insulin on the 24 -h profiles of plasma glucose and insulin concentrations in mid lactation dairy cows. The 2 separately analyzed experiments investigated the effects administering either Humulin $\mathrm{N}(\mathrm{H})$, a neutral protamine Hagedorn insulin, or insulin glargine (Lantus, L), an insulin analog, at doses of 0 (control), 0.1, 0.2, and $0.4 \mathrm{IU} / \mathrm{kg}$ of body weight in a randomized complete block design. Sixteen cows $(237 \pm 11 \mathrm{~d}$ in milk for $\mathrm{H} ; 213 \pm 10 \mathrm{~d}$ in milk for $\mathrm{L}$; mean $\pm \mathrm{SD}$ ) were used for each insulin preparation, resulting in $\mathrm{n}=4$ for each dose within insulin preparation. Cows were fitted with a single jugular catheter on the day before the study. On the day of the study, cows were given treatments by subcutaneous injection of either sterile water or the designated insulin type and dose. Blood samples were taken hourly from the jugular catheter. Subcutaneous injection of both $\mathrm{H}$ and $\mathrm{L}$ resulted in linear decreases in plasma glucose concentrations, increased area under the curve, and decreased nadir for plasma glucose following administration of the insulin preparations. Plasma insulin concentration linearly increased with increasing dose of $\mathrm{H}$. Though elevated concentrations of insulin were measurable in cows treated with $\mathrm{H}$, they were not measurable in cows treated with L. Attempts to measure overall insulin concentrations and metabolites of L by a commercially available ELISA and a commercially available RIA kit were not successful and did not retrieve values that we felt truly represented the amount of insulin activity exhibited during this treatment. Both long-acting insulin preparations elicited insulin-like activity in lactating dairy cows, as evidenced by reduced plasma glucose concentrations. Given these results, the potential exists to use both $\mathrm{H}$ and $\mathrm{L}$ to study the effects of insulin in mid lactation dairy cows without the confounding ef-
\end{abstract}

\footnotetext{
Received October 13, 2011.

Accepted August 17, 2012.

${ }^{1}$ Current address: 1645 N. McCarthy Rd. Apt. 3, Appleton, WI 54913.

${ }^{2}$ Corresponding author: tro2@cornell.edu
}

fect of severe hypoglycemia ( $<20 \mathrm{mg} / \mathrm{dL}$ ) or concurrent provision of glucose during treatment.

Key words: insulin, glucose, dairy cow

\section{INTRODUCTION}

Insulin is a central hormone in the regulation of metabolism in dairy cows, with key roles in glucose (Hayirli, 2006; Aschenbach et al., 2010), lipid (Vernon, 2005) and protein metabolism (Tesseraud et al., 2007). Experimental approaches to study the effects of insulin on metabolism and milk component production in dairy cattle have involved administration of insulin with or without concurrent administration of glucose to maintain euglycemia.

When administered without concurrent administration of glucose, insulin has been associated with reduced milk production, decreased blood glucose, and in some cases clinical signs of moderate to severe hypoglycemia (e.g., hyper- and hypoexcitability, muscle twitching, dullness, or coma; Kronfeld et al., 1963; Schmidt, 1966). In both of these studies, cows recovered with subsequent intravenous administration of glucose.

Because of these complicating effects of moderate to severe hypoglycemia following administration of insulin, most researchers interested in investigating the role of insulin in metabolism of dairy cattle have used the hyperinsulinemic-euglycemic clamp (HEC) technique first described in human subjects (DeFronzo et al., 1979). This technique involves the intravenous infusion of insulin at a constant rate with concurrent intravenous administration of glucose at a variable rate to study the effects of elevated insulin concentrations with maintenance of euglycemia.

The HEC technique has been applied in dairy cattle to study the effects of insulin on milk composition (McGuire et al., 1995; Griinari et al., 1997; Mackle et al., 1999) in cows in established lactation and in the regulation of the somatotropic axis in dairy cows in early and mid lactation (Mashek et al., 2001; Butler et al., 2003). One factor that may complicate interpretation of results from studies involving the HEC technique is the magnitude of the glucose infusion typically administered to maintain euglycemia. As an example, in 
the study by Mackle et al. (1999), more than $3.3 \mathrm{~kg}$ of glucose/d was infused with the HEC.

One other way to potentially elevate circulating concentrations of insulin without the complication of severe hypoglycemia or the confounding associated with infusion of large amounts of glucose would be to administer one of the intermediate- or long-acting insulin or insulin analog preparations commonly used to treat humans with diabetes (reviewed by Sheldon et al., 2009). The use of long-acting insulin in lactating dairy cattle has been limited. Hayirli et al. (2002) administered increasing doses $(0,0.14,0.29$, and $0.43 \mathrm{IU} / \mathrm{kg}$ of BW) of protamine zinc insulin (Humulin, ultralente human insulin rDNA origin in extended zinc suspension) via single intramuscular injection to early lactation cows on d 3 postpartum. Increasing doses of this insulin preparation increased circulating concentrations of insulin and decreased plasma glucose concentrations; 1 cow assigned to the $0.29 \mathrm{IU} / \mathrm{kg}$ of $\mathrm{BW}$ treatment and 2 cows assigned to the $0.43 \mathrm{IU} / \mathrm{kg}$ of BW treatment developed signs of hypoglycemic shock and were removed from study.

We hypothesized that long-acting insulin preparations could be administered to dairy cows in established lactation to elevate circulating insulin concentrations with modest effects on circulating glucose concentrations for application in subsequent experiments to evaluate effects of insulin without concurrent glucose infusion on milk composition. Therefore, the objective of the present study was to evaluate the plasma profiles of glucose and insulin for $24 \mathrm{~h}$ following injection of increasing doses of 2 different preparations of long-acting insulin.

\section{MATERIALS AND METHODS}

\section{Animals, Experimental Design, and Treatments}

The Cornell University Institutional Animal Care and Use Committee approved all procedures involving cows before the onset of the experiment. The 2 insulin preparations were evaluated in 2 consecutive experiments, each involving 16 multiparous Holstein cows in mid lactation. All cows enrolled in this experiment received recombinant bovine somatotropin (rbST; Posilac; Elanco Animal Health, Greenfield, IN) per label starting in the ninth week of lactation and continuing at 2 -wk intervals. Cows were adapted to a common TMR (Table 1) for 7 $\mathrm{d}$ before the day of treatment. Within each experiment, cows were divided into 2 replicate groups $(\mathrm{n}=8)$ and assigned randomly to 1 of 4 treatments. Treatments included control (sterile water), low $(0.1 \mathrm{IU} / \mathrm{kg}$ of BW), medium $(0.2 \mathrm{IU} / \mathrm{kg}$ of $\mathrm{BW})$, and high $(0.4 \mathrm{IU} / \mathrm{kg}$ of $\mathrm{BW}$ ) doses of long-acting insulin. Cows were weighed once on the day before treatment commenced, after the morning milking, and before daily feed delivery, to determine the total dose of the insulin preparation. For the first experiment, cows $(237 \pm 11$ DIM, mean \pm SD, at onset) were administered Humulin $\mathrm{N}[\mathbf{H} ; 100 \mathrm{IU} / \mathrm{mL}$ of human insulin (rDNA origin) isophane suspension; Eli Lilly, Indianapolis, IN] as the form of long-acting insulin. For the second experiment, cows $(213 \pm 10$ $\mathrm{DIM}$, mean $\pm \mathrm{SD}$, at onset) were administered insulin glargine, also known as Lantus $[\mathbf{L} ; 100 \mathrm{IU} / \mathrm{mL}$ of $\mathrm{L}$ (rDNA origin); Sanofi-Aventis US LLC, Bridgewater, NJ) as the form of long-acting insulin.

On the day before treatment commenced in all groups, cows were fitted with an indwelling jugular catheter (Tygon Microbore tubing, 1.778-mm o.d. $\times 1.016-\mathrm{mm}$ i.d.; Norton Performance Plastics, Akron, OH). On the day of treatment, 2 blood samples were collected at 10 and $5 \mathrm{~min}$ before administration of either sterile water or slow-release insulin doses to establish baseline concentrations of glucose and insulin, and were used for covariate data in the statistical analysis. At $0900 \mathrm{~h}$, cows were given treatments via subcutaneous injection in the neck. Blood samples were collected hourly for

Table 1. Dietary ingredients and nutrient composition of the basal diet (DM basis)

\begin{tabular}{lc}
\hline Item & Content \\
\hline Ingredient, \% & \\
Corn silage & 40.5 \\
Alfalfa silage & 16.1 \\
Concentrate mix ${ }^{1}$ & 21.9 \\
Corn meal & 16.0 \\
Corn distillers grain & 5.5 \\
Energy and nutrients ${ }^{2}$ & \\
NE, Mcal/kg & 1.68 \\
CP, \% of DM & 16.1 \\
Soluble protein, \% of CP & 35.1 \\
RDP, \% of CP & 72.6 \\
ADF, \% of DM & 19.3 \\
NDF, \% of DM & 33.6 \\
NFC, \% of DM & 41.8 \\
Ash, \% & 6.3 \\
Ca, \% of DM & 0.70 \\
P, \% of DM & 0.42 \\
Mg, of DM & 0.31 \\
K, \% of DM & 1.27 \\
Na, \% of DM & 0.4 \\
Fe, mg/kg & 185.0 \\
Mn, mg/kg & 62.7 \\
Zn, mg/kg & 83.3 \\
Cu, mg/kg & 16.0 \\
\hline
\end{tabular}

${ }^{1}$ The concentrate mix comprised (DM basis) $35.5 \%$ corn germ meal; $29.0 \%$ wheat middlings, $12.6 \%$ canola meal, $5.6 \%$ calcium carbonate, 4.7\% whey permeate, $3.9 \%$ blood meal, $2.5 \%$ sodium bicarbonate, $2.2 \%$ salt, $2.0 \%$ urea, $0.8 \%$ Optigen II (Alltech, Lexington, KY), $0.6 \%$ magnesium oxide, $0.2 \%$ calcium sulfate, $0.06 \%$ selenium , $0.1 \%$ trace minerals, 0.1\% Agrado (Novus International Inc., St. Louis, MO), $0.1 \%$ vitamin $\mathrm{A} / \mathrm{D} / \mathrm{E}$, and $0.1 \%$ Rumensin (Elanco, Indianapolis, IN).

${ }^{2}$ Values represent average values of TMR samples taken on each day of treatment. 
$24 \mathrm{~h}$ via jugular catheter and blood was transferred to tubes containing sodium heparin (30 U of heparin/mL of blood) and placed immediately on ice. To monitor cows for existence of severe hypoglycemia ( $<20 \mathrm{mg} /$ $\mathrm{dL}$ ), blood glucose concentrations were measured immediately on all samples using a hand-held blood glucose meter with test strips (Precision Xtra; Abbott Laboratories, Abbott Park, IL). Blood samples were centrifuged $\left(3,000 \times g\right.$ for $20 \mathrm{~min}$ at $\left.4^{\circ} \mathrm{C}\right)$ within 15 min after collection and plasma was harvested into 3 aliquots, snap frozen with liquid $\mathrm{N}_{2}$, and then stored at $-20^{\circ} \mathrm{C}$ until analysis for glucose and insulin.

A common TMR was fed to all cows for ad libitum intake and was formulated to meet NRC nutrient recommendations (NRC, 2001). During the diet adaptation period, fresh feed was provided each morning at $0900 \mathrm{~h}$, orts were weighed and recorded daily, and water was made available at all times. On the day of sampling, feed was delivered hourly starting immediately after treatment administration at $0900 \mathrm{~h}$ to minimize fluctuations in circulating metabolites and hormones influenced by feed intake. Samples of the TMR were taken on the day of treatment and sent to Cumberland Valley Analytical Services (Hagerstown, MD) for analysis using AOAC International (2000) wet chemistry techniques for $\mathrm{CP}$, acid detergent insoluble $\mathrm{CP}$ (determined after acid detergent extraction), neutral detergent insoluble CP [after neutral detergent extraction (Van Soest et al., 1991)], NDF, and ash content determination. Soluble CP (Krishnamoorthy et al., 1982) and ADF (AOAC International, 2000) concentrations were also determined. Dietary ingredients and chemical composition of the basal TMR are reported in Table 1. Cows were milked 3 times daily at 0700, 1500, and $2300 \mathrm{~h}$ during the adaptation period and on the day of treatment and sample collection.

\section{Plasma Metabolite and Hormone Analysis}

Plasma concentrations of glucose were determined by enzymatic analysis (glucose oxidase) using commercially available reagents (P7119, PGO enzyme preparation; F5803, 3,3'-dimethoxybenzidine dihydrochloride; Sigma Aldrich, St. Louis, MO). Intraassay and interassay coefficients of variation for glucose analysis were 2.6 and $3.3 \%$, respectively. Spectrophotometric readings were made using a VersaMax tunable microplate reader (Molecular Devices LLC, Sunnyvale, CA).

Plasma insulin concentrations were measured using 2 commercially available kits. First, a bovine insulin ELISA kit reported to exhibit $28 \%$ cross-reactivity with L (Mercodia AB, Uppsala, Sweden) was used to measure the insulin values in the hourly plasma samples. Intraassay and interassay coefficients of variation for the
ELISA were 4.3 and $6.4 \%$, respectively. Plasma insulin concentrations were also determined by a commercially available RIA kit, which has $90 \%$ cross-reactivity with native bovine insulin (no. PI-12K porcine insulin RIA; Linco Research, St. Charles, MO). Intraassay and interassay coefficients of variation for the RIA insulin analysis were 9.2 and $9.7 \%$, respectively.

\section{Statistical Analysis}

Data were analyzed as 2 separately conducted experiments. Within each preparation of long-acting insulin, data for plasma glucose and insulin concentrations collected over time were analyzed using the MIXED procedure of SAS (SAS Institute, 2001). Fixed effects in the model included treatment dose, hour, and the interaction of dose and hour. Repeated measures for hour were included in the REPEATED statement. Group was included as a random effect in the model. Data for DMI collected on the day of treatment were analyzed using the MIXED procedure of SAS (SAS Institute, 2001) with the fixed effect of dose and the random effect of group in the model. Covariate data points collected before treatments commenced were used for covariate adjustment in the model. In addition to repeated measures analyses for plasma glucose, the nadir glucose concentration and the time to nadir was determined and the area under the curve (AUC) for plasma glucose was calculated using incremental change from baseline concentrations and the trapezoidal rule using the EXPAND procedure of SAS. Data relating to the nadir and AUC analyses were analyzed using the MIXED procedure of SAS, with the fixed effect of dose and the random effect of group in the model.

\section{RESULTS AND DISCUSSION}

Sixteen cows completed the first experiment using $\mathrm{H}$ as the long-acting insulin preparation of interest. For the experiment using $\mathrm{L}$ as the long-acting insulin preparation of interest, 1 control cow was dropped from the experiment before treatment commenced due to a mobility issue unrelated to the experiment, resulting in 15 cows being used in the data analysis. On the day of treatment, DMI was not different between doses for cows given either type of long-acting insulin. Dry matter intakes for cows treated with $\mathrm{H}$ were as follows: $27.9,27.5,29.4$, and $29.0 \pm 1.6 \mathrm{~kg}$ (mean $\pm \mathrm{SE}$ ) for the $0,0.1,0.2$, and $0.4 \mathrm{IU} / \mathrm{kg}$ of BW doses, respectively $(P$ $=0.83)$. For cows treated with $\mathrm{L}, \mathrm{DMI}$ on the day of treatment were as follows: 29.1, 29.5, 28.3, and $25.7 \pm$ $2.5 \mathrm{~kg}$ (mean $\pm \mathrm{SE}$ ) for the $0,0.1,0.2$, and 0.4 doses respectively $(P=0.62)$. Although no overall effect of treatment dose on DMI was observed for the cows 
treated with $\mathrm{L}$, the cows treated with the highest dose of L had numerically lower DMI; however, no linear or quadratic effect of L dose on DMI (linear: $P=0.28$; quadratic: $P=0.53)$ was observed.

In ruminants, the effects of insulin on feed intake are variable. In a study designed to test the effect of insulin on long- and short-term feeding behavior, Baile and Mayer (1968) did not observe any changes in intake with insulin treatment and severe hypoglycemia. Insulin effects on DMI were more variable in sheep (Deetz et al., 1980), sometimes causing a decrease in intake but at other times having no effect on intake, depending on dose or route of administration. Hayirli et al. (2002) observed a tendency for a quadratic effect of slow-release insulin on intake such that early lactation cows who received a dose of $0.14 \mathrm{IU} / \mathrm{kg}$ had slightly higher DMI than controls or cows administered 0.29 or $0.43 \mathrm{IU} /$ $\mathrm{kg}$ of insulin. In the experiments by Kronfeld et al. (1963), several cows became recumbent and depressed during treatment with successive doses of insulin, and during these severe hypoglycemic episodes, the authors reported that the cows did not eat. Thus, it appears that insulin can have varied effects on ruminants, depending on the dosage rate and type of insulin administered. The overall goal of the present experiment was to determine whether long-acting insulin preparations can be used to elevate insulin activity without the need to infuse glucose to maintain glycemia within normal ranges. With the observation of a numerical decrease in intake at the highest dose of $\mathrm{L}$, we are hesitant to use that dose in studies of longer duration because of potential concern for severe hypoglycemia.

Responses of plasma glucose following administration of $\mathrm{H}$ are described in Figure 1 (panel A) and Table 2. Plasma glucose concentrations over the 24-h postinjection period were decreased linearly $(P<0.001)$ with increasing dose of $\mathrm{H}$ (Figure 1, panel A). Over the 24-h sampling period, mean plasma glucose concentrations were 3.1, 5.6, and $9.4 \%$ lower for the $0.1,0.2$, and $0.4 \mathrm{IU}$ of $\mathrm{H} / \mathrm{kg}$ of BW treatments compared with the control, respectively. Glucose concentrations were $62.1(95 \%$ CI: 60.7-63.6), 60.2 (95\% CI: 58.7-61.7), 58.7 (95\% CI: $57.2-60.2$ ), and 56.3 (95\% CI: $54.9-57.8) \mathrm{mg} / \mathrm{dL}$ for the control and the $0.1,0.2$, and $0.4 \mathrm{IU}$ of $\mathrm{H} / \mathrm{kg}$ of BW treatments, respectively (linear effect of dose: $P<$ 0.001). The AUC for plasma glucose (calculated as a decrement from baseline concentrations) was increased linearly during both the first 12 -h $(P<0.001)$ and 24-h $(P<0.003)$ following $\mathrm{H}$ administration (Table 2$)$. Increasing doses of $\mathrm{H}$ linearly decreased $(P<0.001)$ the nadir concentration of plasma glucose, with cows administered $0.4 \mathrm{IU}$ of $\mathrm{H} / \mathrm{kg}$ of $\mathrm{BW}$ having a mean nadir plasma glucose concentration of $42.1 \mathrm{mg} / \mathrm{dL}$ (Table 2). Although time to the nadir concentration
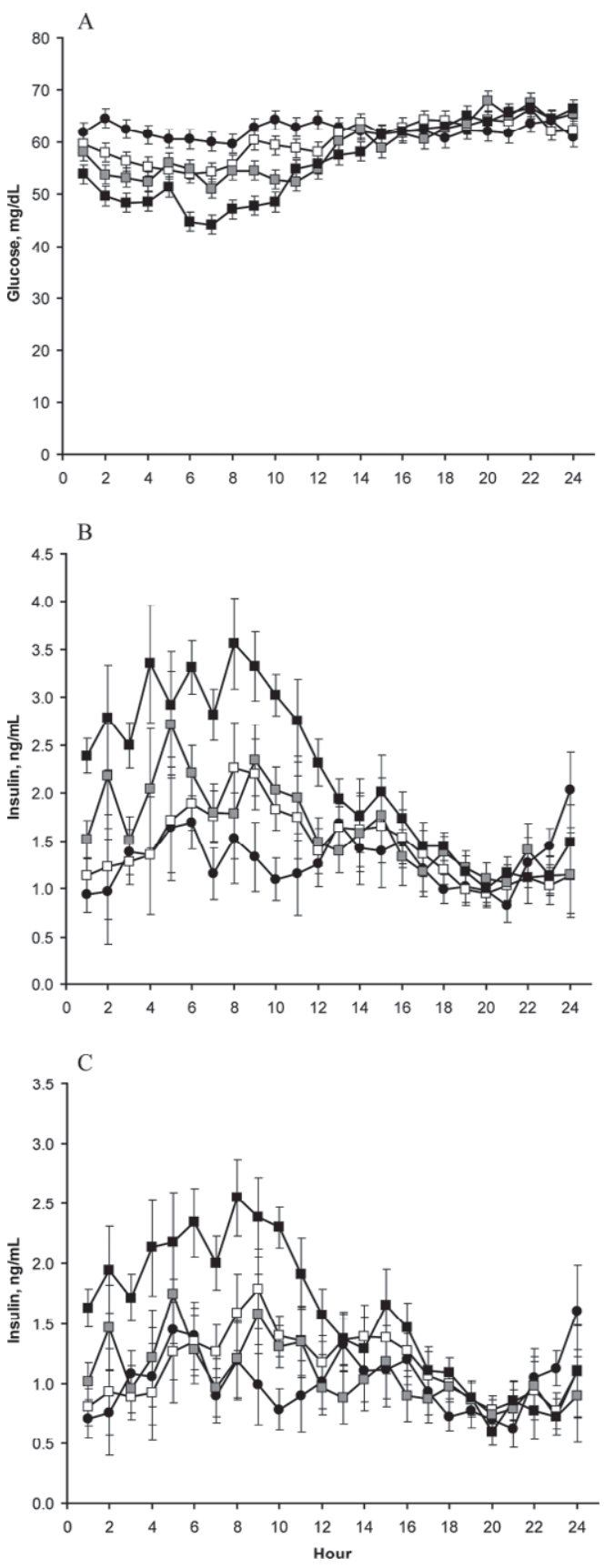

Figure 1. Plasma concentrations of glucose (panel A) and insulin (panels B and C) for cows injected subcutaneously with sterile water (solid circles) or 0.1 (open squares), 0.2 (gray squares), or 0.4 (solid squares) IU of Humulin N/ kg of BW. Panel A (plasma glucose): effects of dose, hour, and dose $\times$ hour interaction were $P<0.001, P<0.001$, and $P<0.001$, respectively. A linear decrease $(P<0.001)$ in plasma glucose was observed with increasing dose of Humulin-N treatment. Panel B (plasma insulin values as measured by the Mercodia bovine insulin ELISA; Mercodia AB, Uppsala, Sweden): effects of dose, hour, and dose $\times$ hour interaction were $P<0.001, P<0.001$, and $P=$ 0.29 , respectively. A linear increase $(P<0.001)$ in plasma insulin was observed with increasing dose of Humulin $\mathrm{N}$ treatment. Panel $\mathrm{C}$ (plasma insulin values as measured by RIA): effects of dose, hour, and dose $\times$ hour interaction were $P<0.001, P<0.001$, and $P=0.28$, respectively. A linear increase $(P<0.001)$ in ELISA insulin values was observed with increasing dose of Humulin $\mathrm{N}$ treatment. 
of plasma glucose was not affected by treatment, cows administered 0.2 and $0.4 \mathrm{IU}$ of $\mathrm{H} / \mathrm{kg}$ of $\mathrm{BW}$ reached the nadir at 7.0 and $5.5 \mathrm{~h}$ on average, respectively, following injection. Based on work with a similar slow-release insulin by Hayirli et al. (2002), we expected that H would decrease plasma glucose concentrations in the current experiment. Although the reductions in plasma glucose observed in the current study were not as large as the decreases observed by Hayirli et al. (2002), it should be noted that the type of slow-release insulin used in that study was not exactly the same as the type used in this study, routes of administration were different (intramuscular vs. subcutaneous in the present study), stage of lactation was different (early vs. mid lactation), and rbST status was different (nontreated vs. treated).

Responses of plasma glucose following administration of L are described in Figure 2 (panel A) and Table 3. Plasma glucose concentrations over the 24-h postinjection period decreased linearly $(P<0.001)$ with increasing dose of L (Figure 2, panel A). For the cows treated with subcutaneous injections of L, plasma glucose concentrations were $5.6,7.5$, and $17.9 \%$ lower than the controls for the $0.1,0.2$, and $0.4 \mathrm{IU} / \mathrm{kg}$ of BW doses, respectively (effect of dose: $P<0.001$; linear: $P$ $<0.001)$. Over the 24 -h sampling period, glucose concentrations were 66.0 (95\% CI: 62.0-70.0), 62.3 (95\% CI: 59.3-65.2), 61.0 (95\% CI: 57.6-64.4), and $54.1(95 \%$ CI: $50.2-58.0) \mathrm{mg} / \mathrm{dL}$ for the control and the $0.1,0.2$, and $0.4 \mathrm{IU}$ of $\mathrm{L} / \mathrm{kg}$ of $\mathrm{BW}$ treatments, respectively. The AUC for plasma glucose (calculated as a decrement from baseline concentrations) was increased linearly during both the first 12 -h $(P<0.008)$ and 24 -h $(P<$ 0.02 ) following $\mathrm{L}$ administration (Table 3 ). Increasing doses of L linearly decreased $(P<0.003)$ the nadir concentration of plasma glucose, with cows administered $0.4 \mathrm{IU}$ of $\mathrm{L} / \mathrm{kg}$ of BW having a mean nadir plasma glucose concentration of $43.2 \mathrm{mg} / \mathrm{dL}$ (Table 2). Although time to the nadir concentration of plasma glucose was not affected by treatment, cows administered 0.2 and $0.4 \mathrm{IU}$ of $\mathrm{L} / \mathrm{kg}$ of BW reached the nadir at 9.2 and 9.5 $\mathrm{h}$ on average, respectively, following injection. To our knowledge, L has never been administered to lactating dairy cows or any ruminants. Although we expected that L would exhibit insulin-like activity in dairy cows, we were unsure to what extent plasma glucose would be decreased following $\mathrm{L}$ injection.

As described above, we were interested in monitoring the cows during this experiment for occurrence of severe hypoglycemia (plasma glucose $<20 \mathrm{mg} / \mathrm{dL}$ ); therefore, characterization of individual responses to the insulin injections are of interest, in addition to the average nadir responses by form and dose. Individual nadir plasma glucose values are depicted in Figure 3 (panel $\mathrm{A}$ for $\mathrm{H}$ and panel $\mathrm{B}$ for $\mathrm{L}$ ). In all cases, the nadir value for glucose was higher than $30 \mathrm{mg} / \mathrm{dL}$.

The first insulin assay used to attempt to measure plasma insulin was the Mercodia bovine insulin ELISA (Mercodia AB). The cross-reactivity data from Mercodia stated the ELISA exhibited $28 \%$ cross-reactivity with L. Many other insulin assays do not state crossreactivity with L, so this ELISA seemed like a logical starting point for insulin analyses.

When plasma insulin was measured by the Mercodia bovine insulin ELISA, a linear increase in plasma insulin was observed with increasing dose of $\mathrm{H}$ (Figure 1, panel B). For cows treated with $\mathrm{H}$, plasma insulin was increased by $12.1,25.6$, and $67.9 \%$ for the $0.1,0.2$, and $0.4 \mathrm{IU} / \mathrm{kg}$ of $\mathrm{BW}$ doses, respectively (effect of dose: $P<0.001$; linear: $P<0.001)$. Insulin concentrations were $($ mean $\pm \mathrm{SE}) 1.30,1.46,1.64$, and $2.19 \pm 0.143$ $\mathrm{ng} / \mathrm{mL}$ for the control and the 0.1, 0.2, and $0.4 \mathrm{IU}$ of $\mathrm{H} / \mathrm{kg}$ of $\mathrm{BW}$ doses, respectively. On the other hand, when looking at the cows treated with $\mathrm{L}$, the results from the ELISA suggest that the assay does not exhibit cross-reactivity with the $\mathrm{L}$ metabolites. Using data unadjusted for cross-reactivity from the ELISA, cows treated with increasing doses of L had linearly lower

Table 2. Area under the curve (AUC), nadir concentration, and time to nadir concentration for plasma glucose following administration of neutral protamine Hagedorn insulin $(\mathrm{H})$

\begin{tabular}{|c|c|c|c|c|c|c|c|}
\hline \multirow[b]{2}{*}{ Item } & \multicolumn{4}{|c|}{ Treatment, IU $/ \mathrm{kg}$ of BW } & \multirow[b]{2}{*}{ SEM } & \multicolumn{2}{|c|}{ Effect, $P$-value } \\
\hline & 0 & 0.1 & 0.2 & 0.4 & & Linear & Quadratic \\
\hline $\operatorname{AUC}(12 \mathrm{~h})^{1}$ & 39.2 & 96.2 & 145.5 & 186.3 & 19.4 & 0.001 & 0.60 \\
\hline $\operatorname{AUC}(24 \mathrm{~h})^{2}$ & 76.8 & 120.9 & 190.0 & 220.3 & 29.8 & 0.003 & 0.82 \\
\hline Nadir glucose, ${ }^{3} \mathrm{mg} / \mathrm{dL}$ & 56.3 & 52.4 & 50.8 & 42.1 & 2.2 & 0.001 & 0.28 \\
\hline Time to nadir, ${ }^{4} \mathrm{~h}$ & 7.5 & 9.2 & 7.0 & 5.5 & 2.9 & 0.30 & 0.36 \\
\hline
\end{tabular}


values in the ELISA (Figure 2, panel B) and the least squares means for the 24 -h sampling period were (mean $\pm \mathrm{SE}) 1.21,0.89,0.79$, and $0.58 \pm 0.092 \mathrm{ng} / \mathrm{mL}$ for the control and the $0.1,0.2$, and $0.4 \mathrm{IU}$ of $\mathrm{L} / \mathrm{kg}$ of $\mathrm{BW}$ doses, respectively (effect of dose: $P<0.001$; linear: $P<$ 0.001). Intuitively, if the ELISA did in fact cross-react with L, then, even with reduced overall cross-reactivity, greater values from the ELISA would be expected with increasing doses of $\mathrm{L}$. This was not the case, suggesting a few plausible explanations. First, the ELISA may be detecting endogenous concentrations of native bovine insulin. With insulin activity from exogenous sources in the system and lower circulating blood glucose concentrations, it would seem likely that the pancreas would secrete less insulin. Insulin supplied to an in situ perfused pancreas suppressed endogenous insulin secretion (Stagner et al., 1986). Addition of an insulin-mimetic adipokine (visfatin) to clonal mouse pancreatic $\beta$-cells reduced insulin secretion by the $\beta$-cells (Brown et al., 2010). The work by Stagner et al. (1986) and Brown et al. (2010) both support the concept that endogenous insulin production would be downregulated in the present study for cows treated with L. Alternatively, the L metabolites in the plasma samples may interfere with the ELISA antibody's ability to bind with insulin. That is, as more L metabolites are in circulation with increasing dose of $\mathrm{L}$, there may be increasing interference in the assay, leading to reduced values in the ELISA. Finally, in detailed work with human insulin assays and detection of L, Agin et al. (2007) forced solubilization of the L molecule into its metabolites before submitting it to the assays, thus mimicking the natural precipitation of $\mathrm{L}$ that occurs as it adjusts to physiological $\mathrm{pH}$. If the cross-reactivity of L with the ELISA was tested on the L molecule, as opposed to breaking it down into its metabolites and then testing the cross-reactivity, the results reported in the kit information may be inaccurate.

To obtain a better idea of how much insulin-like activity was present in the cows treated with $\mathrm{L}$, another insulin assay was used. The results reported here represent values from the porcine insulin RIA that were unadjusted for cross-reactivity and, as previously noted, this assay exhibits $90 \%$ cross-reactivity with bovine insulin. For cows treated with $\mathrm{H}$, a linear increase $(P$ $<0.001)$ in plasma insulin concentrations was observed with increasing dose of $\mathrm{H}(1.02,1.15,1.08$, and $1.57 \pm$ $0.097 \mathrm{ng} / \mathrm{mL}$ for the control and the 0.1, 0.2, and 0.4 $\mathrm{IU} / \mathrm{kg}$ of $\mathrm{BW}$ doses, respectively; mean $\pm \mathrm{SE}$ ). The 24-h profile of insulin values for cows treated with $\mathrm{H}$ is shown in Figure 1, panel C. When results from the RIA were compared with those from the ELISA, the insulin values obtained with the RIA were between 21 and $34 \%$ lower than those obtained from the ELISA, keeping in
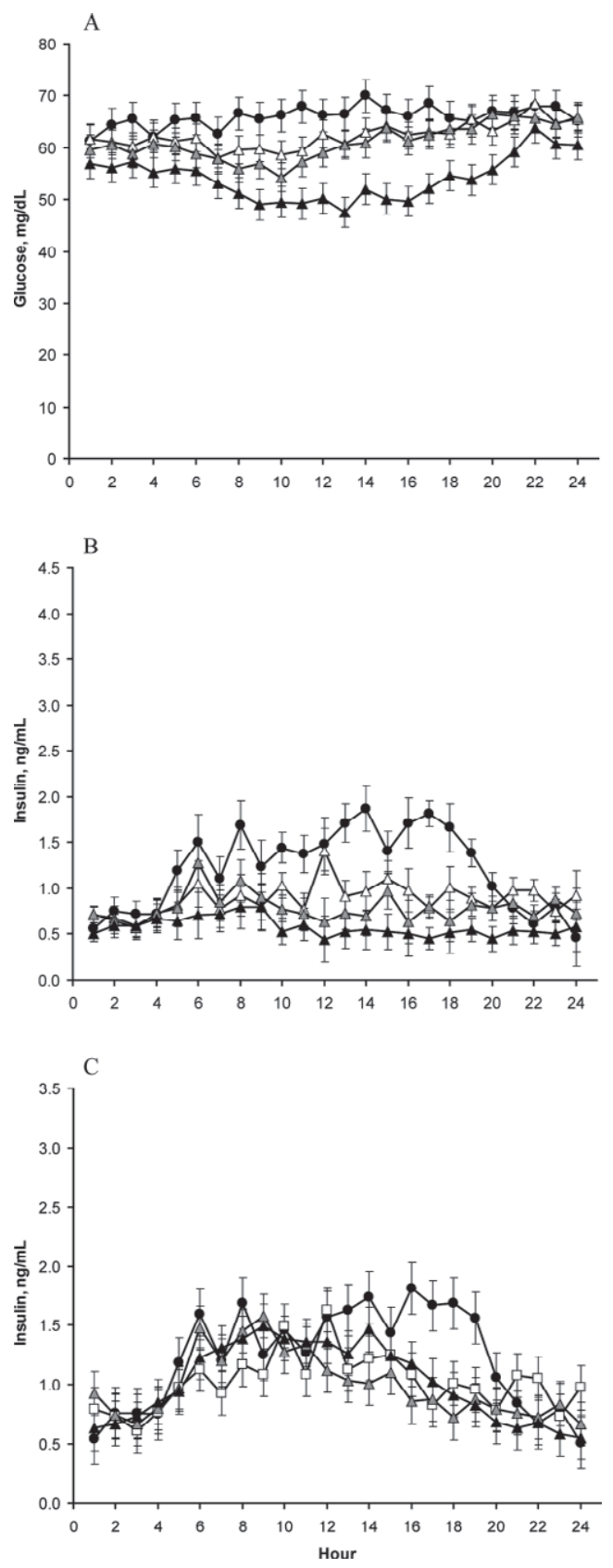

Figure 2. Plasma concentrations of glucose (panel A) and insulin (panels B and C) for cows injected subcutaneously with sterile water (solid circles) or 0.1 (open triangles), 0.2 (gray triangles), or 0.4 (solid triangles) IU of insulin glargine $/ \mathrm{kg}$ of $\mathrm{BW}$. Panel A (plasma glucose): effects of dose, hour, and dose $\times$ hour interaction were $P=$ $0.002, P=0.002$, and $P=0.32$, respectively. A linear decrease $(P<$ 0.001 ) in plasma glucose was observed with increasing dose of insulin glargine treatment. Panel B (plasma insulin values, as measured by the Mercodia bovine insulin ELISA; Mercodia AB, Uppsala, Sweden): effects of dose, hour, and dose $\times$ hour interaction were $P<0.001, P$ $=0.002$, and $P=0.012$, respectively. A linear decrease $(P<0.001)$ in ELISA insulin values was observed with increasing dose of insulin glargine treatment. Panel C (plasma insulin values as measured by RIA): effects of dose, hour, and dose $\times$ hour interaction were $P=0.14$, $P<0.001$, and $P=0.23$, respectively. A linear decrease $(P=0.07)$ of RIA insulin values was observed with increasing dose of insulin glargine treatment. 
Table 3. Area under the curve (AUC), nadir concentration, and time to nadir concentration for plasma glucose following administration of insulin glargine (L)

\begin{tabular}{|c|c|c|c|c|c|c|c|}
\hline \multirow[b]{2}{*}{ Item } & \multicolumn{4}{|c|}{ Treatment, IU $/ \mathrm{kg}$ of BW } & \multirow[b]{2}{*}{ SEM } & \multicolumn{2}{|c|}{ Effect, $P$-value } \\
\hline & 0 & 0.1 & 0.2 & 0.4 & & Linear & Quadratic \\
\hline $\operatorname{AUC}(12 \mathrm{~h})^{1}$ & 26.3 & 53.3 & 98.5 & 120.9 & 24.5 & 0.008 & 0.92 \\
\hline AUC $(24 \mathrm{~h})^{2}$ & 27.7 & 67.2 & 114.1 & 233.2 & 58.7 & 0.02 & 0.47 \\
\hline Nadir glucose, ${ }^{3} \mathrm{mg} / \mathrm{dL}$ & 62.7 & 54.7 & 53.4 & 43.2 & 3.9 & 0.003 & 0.75 \\
\hline Time to nadir, ${ }^{4} \mathrm{~h}$ & 11.0 & 6.5 & 9.2 & 9.5 & 3.1 & 0.89 & 0.37 \\
\hline
\end{tabular}

mind that the RIA results were not corrected for the 90\% cross-reactivity. Thus, with correction for crossreactivity, the difference would become smaller.

For the cows treated with L, no overall effect of treatment was observed for the values obtained from the RIA $(P=0.14 ; 1.22,1.02,0.99$, and $1.02 \pm 0.089 \mathrm{ng} /$ $\mathrm{mL}$ for the control and the $0.1,0.2$, and $0.4 \mathrm{IU}$ of $\mathrm{L} /$ $\mathrm{kg}$ of BW treatments, respectively, with no adjustment for assay $90 \%$ cross-reactivity of the RIA; mean \pm SE). The 24-h profiles of insulin values obtained by RIA are shown in Figure 2 (panel $\mathrm{C}$ ) and a linear effect of $\mathrm{L}$ on insulin values was observed for this assay $(P=0.07)$. Taken collectively with the results from the ELISA, it would seem plausible that the $\mathrm{L}$ metabolites interfere with the antibody binding in the ELISA, thus showing reduced values in the assay for cows treated with increasing doses of $\mathrm{L}$.

In selection of the assays used to measure insulin activity following injection with long-acting insulin preparations, the cross-reactivity of the 2 preparations to the antibodies in the assays was considered. Humulin-N is produced by a laboratory strain of Escherichia coli that has been genetically altered to produce human insulin, making the structure of $\mathrm{H}$ homologous to human insulin. As human insulin and bovine insulin are different by only 3 AA (Figure 4), depending on epitope location on the antibody, commercially available insulin assays should be able measure $\mathrm{H}$ in plasma.

On the other hand, L has important structural modifications (Figure 4) that alter its ability to be detected by commercially available insulin assays. When given subcutaneously, the $\mathrm{L}$ molecule is solubilized into 2 metabolites, M1 and M2 (Kuerzel et al., 2003; Agin et al., 2007). The cross-reactivity of $\mathrm{L}$ and its metabolites with antibodies to human insulin is lower than reactivity with native insulin. Immunoaffinity chromatography followed by liquid chromatography-mass spectrometry can detect L metabolites in urine (Thomas et al., 2007); however, no urine samples were taken during our set of experiments for that type of analysis. In later experiments, this method could be explored as a potential way to measure $\mathrm{L}$ metabolites in bovine urine.

Although insulin activity was likely not measurable in the plasma samples taken from cows treated with $\mathrm{L}$, the overall goal was to find a research model that could be used to extend the information learned from HEC.
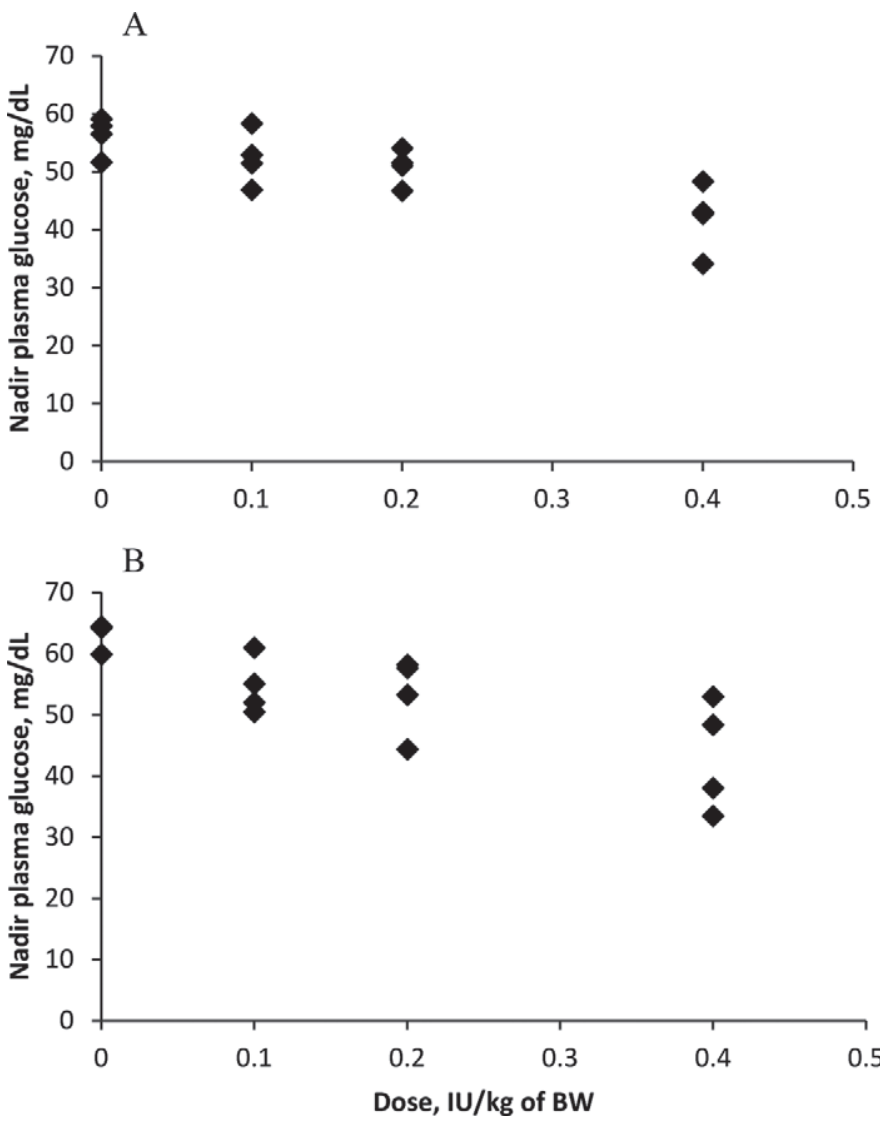

Figure 3. Nadir concentrations of glucose from individual cows injected subcutaneously with sterile water $(0)$ or $0.1,0.2$, or $0.4 \mathrm{IU}$ of either Humulin-N (panel A) or insulin glargine (panel B) per kilogram of BW. 


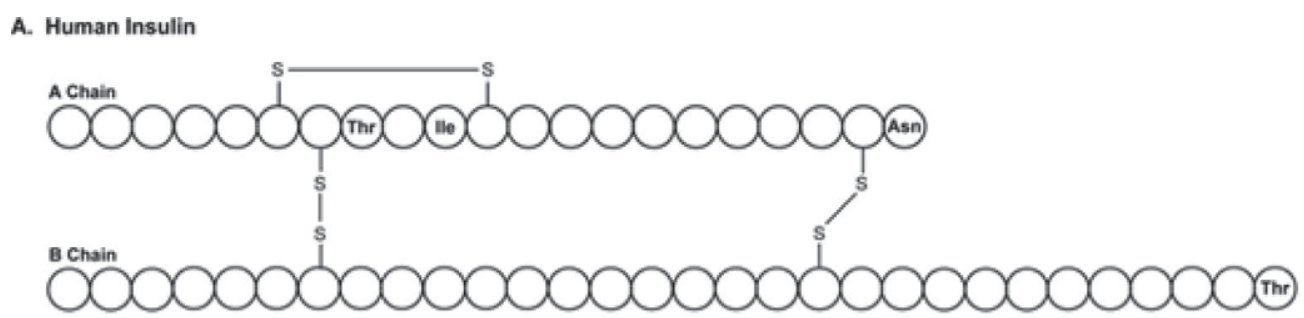

B. Bovine Insulin

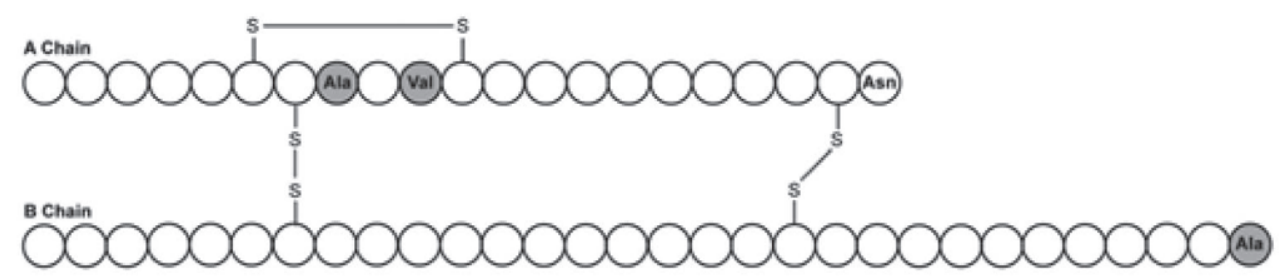

c. Insulin Glargine

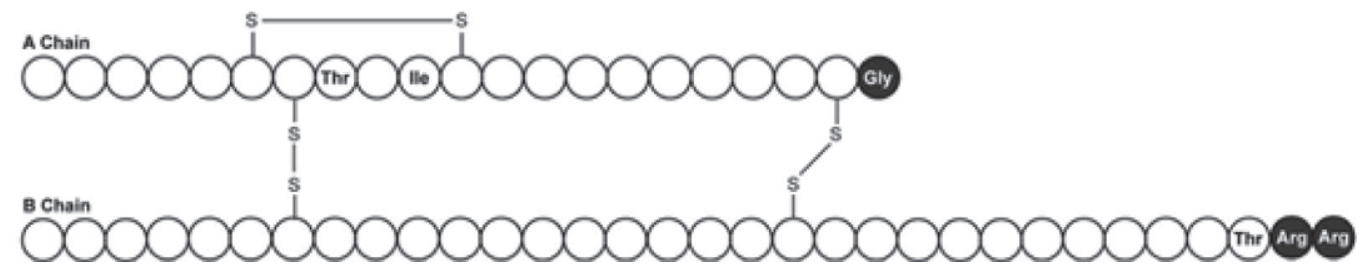

Figure 4. Human insulin (A), bovine insulin (B), and insulin glargine (C) amino acid homology. Bovine insulin differs from human insulin by 3 AA, including an Ala substitution for Thr at AA 8 on the A chain and AA 30 on the B chain, and a Val substitution for Ile at AA 10 on the A chain. For insulin glargine, the base AA structure is similar to human insulin except for a Gly substitution for Asn on the carboxyl end of the A chain and the addition of 2 Arg residues on the carboxyl end of the B chain. Disulfide bonds $(-\mathrm{S}-\mathrm{S}-)$ are indicated.

Both long-acting insulin types reported here exhibited insulin activity in lactating dairy cows, as evidenced by reduced plasma glucose concentrations during the 24-h period following injection.

\section{CONCLUSIONS}

Both preparations of long-acting insulin were able to effectively reduce circulating plasma glucose concentrations in mid lactation cows without severe hypoglycemia in this short-term study. This suggests potential to use these forms of insulin as alternatives to HEC to investigate the effects of elevated insulin activity in mid lactation dairy cows.

\section{ACKNOWLEDGMENTS}

We thank Eli Lilly and Co. (Indianapolis, IN) for providing the Humulin-N used in this experiment. Additionally, we thank Katie Schoenberg, Charlene Ryan, Julie Huzzey, Jennine Ropke, and Fernanda Vieira (all at Cornell University, Ithaca, NY) for their assistance with catheterization of the cows and sample collection.
Finally, we thank Ray Axtell, Gladys Birdsall, and all of the workers at the Cornell Teaching and Research Center (Ithaca, NY) for their assistance during the experiment and daily care of the cows. This work was supported in part by Multistate Research Funds allocated to the Cornell University Agricultural Experiment Station (Ithaca, NY).

\section{REFERENCES}

Agin, A., N. Jeandidier, F. Gasser, D. Grucker, and R. Sapin. 2007. Glargine blood biotransformation: In vitro appraisal with human insulin immunoassay. Diabetes Metab. 33:205-212.

AOAC International. 2000. Official Methods of Analysis. 17th ed. AOAC International, Gaithersburg, MD.

Aschenbach, J. R., N. B. Kristensen, S. S. Donkin, H. M. Hammon, and G. B. Penner. 2010. Gluconeogenesis in dairy cows: The secret of making sweet milk from sour dough. IUBMB Life 62:869-877.

Baile, C. A., and J. Mayer. 1968. Effects of insulin-induced hypoglycemia and hypoacetoemia on eating behavior in goats. J. Dairy Sci. 51:1495-1499.

Brown, J. E. P., D. J. Onyango, M. Ramanjaneya, A. C. Conner, S. T. Patel, S. J. Dunmore, and H. S. Randeva. 2010. Visfatin regulates insulin secretion, insulin receptor signalling and mRNA expression of diabetes-related genes in mouse pancreatic $\beta$-cells. J. Mol. Endocrinol. 44:171-178.

Butler, S. T., A. L. Marr, S. H. Pelton, R. P. Radcliff, M. C. Lucy, and W. R. Butler. 2003. Insulin restores GH responsiveness dur- 
ing lactation-induced negative energy balance in dairy cattle: Effects on expression of IGF-I and GH receptor 1A. J. Endocrinol. 176:205-217.

Deetz, L. E., P. J. Wangsness, J. F. Kavanaugh, and L. C. Griel Jr. 1980. Effect of intraportal and continuous intrajugular administration of insulin on feeding in sheep. J. Nutr. 110:1983-1991.

DeFronzo, R. A., J. D. Tobin, and R. Andres. 1979. Glucose clamp technique: A method for quantifying insulin secretion and resistance. Am. J. Physiol. 237:E214-E223.

Griinari, J. M., M. A. McGuire, D. A. Dwyer, D. E. Bauman, D. M. Barbano, and W. A. House. 1997. The role of insulin in the regulation of milk protein synthesis in dairy cows. J. Dairy Sci. 80:2361-2371.

Hayirli, A. 2006. The role of exogenous insulin in the complex of hepatic lipidosis and ketosis associated with insulin resistance phenomenon in postpartum dairy cattle. Vet. Res. Commun. 30:749-774.

Hayirli, A., S. J. Bertics, and R. R. Grummer. 2002. Effects of slowrelease insulin on production, liver triglyceride, and metabolic profiles of Holsteins in early lactation. J. Dairy Sci. 85:2180-2191.

Krishnamoorthy, U., T. V. Muscato, C. J. Sniffen, and P. J. Van Soest. 1982. Nitrogen fractions in selected feedstuffs. J. Dairy Sci. 65:217-225.

Kronfeld, D. S., G. P. Mayer, J. McD. Robertson, and F. Raggi. 1963. Depression of milk secretion during insulin administration. J. Dairy Sci. 46:559-563.

Kuerzel, G. U., U. Shukla, H. E. Scholtz, S. G. Pretorius, D. H. Wessels, C. Venter, M. A. Potgieter, A. M. Lang, T. Koose, and E. Bernhardt. 2003. Biotransformation of insulin glargine after subcutaneous injection in healthy subjects. Curr. Med. Res. Opin. 19:34-40

Mackle, T. R., D. A. Dwyer, K. L. Ingvartsen, P. Y. Chouinard, J. M. Lynch, D. M. Barbano, and D. E. Bauman. 1999. Effects of insulin and amino acids on milk protein concentration and yield from dairy cows. J. Dairy Sci. 82:1512-1524.
Mashek, D. G., K. L. Ingvartsen, J. B. Andersen, M. Vestergaard, and T. Larsen. 2001. Effects of a four-day hyperinsulinemic-euglycemic clamp in early and mid-lactation dairy cows on plasma concentrations of metabolites, hormones, and binding proteins. Domest. Anim. Endocrinol. 21:169-185.

McGuire, M. A., J. M. Griinari, D. A. Dwyer, and D. E. Bauman. 1995. Role of insulin in the regulation of mammary synthesis of fat and protein. J. Dairy Sci. 78:816-824.

NRC. 2001. Nutrient Requirements of Dairy Cattle. 7th rev. ed. Natl. Acad. Press, Washington, DC.

SAS Institute. 2001. SAS User's Guide: Statistics, Version 8 ed. SAS Inst. Inc, Cary, NC.

Schmidt, G. H. 1966. Effect of insulin on yield and composition of milk of dairy cows. J. Dairy Sci. 49:381-385.

Sheldon, B., J. B. Russell, and J. Wright. 2009. Insulin analogues: An example of applied medical science. Diabetes Obes. Metab. 11:5-19.

Stagner, J., E. Samols, K. Polonsky, and W. Pugh. 1986. Lack of direct inhibition of insulin secretion by exogenous insulin in the canine pancreas. J. Clin. Invest. 78:1193-1198.

Tesseraud, S., S. Métayer, S. Duchêne, K. Bigot, J. Grizard, and J. Dupont. 2007. Regulation of protein metabolism by insulin: Value of different approaches and animal models. Domest. Anim. Endocrinol. 33:123-142.

Thomas, A., M. Thevis, P. Delahaut, A. Bosseloir, and W. Schänzer. 2007. Mass spectrometric identification of degradation products of insulin and its long-acting analogues in human urine for doping control purposes. Anal. Chem. 79:2518-2524.

Van Soest, P. J., J. B. Robertson, and B. A. Lewis. 1991. Methods for dietary fiber, neutral detergent fiber, and nonstarch polysaccharides in relation to animal nutrition. J. Dairy Sci. 74:3583-3597.

Vernon, R. G. 2005. Lipid metabolism during lactation: A review of adipose tissue-liver interactions and the development of fatty liver. J. Dairy Res. 72:460-469. 